\title{
Trickster-Like Teachings in Tibetan Buddhism: Shortcuts towards Destroying Illusions
}

\author{
Z. G. $\mathrm{Ma}^{1^{*}}$ \\ ${ }^{1}$ California Institute of Integral Studies (CIIS), California, USA.
}

Author's contribution

The sole author designed, analyzed and interpreted and prepared the manuscript.

Article Information

DOI: $10.9734 / A R J A S S / 2018 / 38108$

Editor(s):

(1) Shiro Horiuchi, Faculty of International Tourism, Hannan University, Japan.

(2) David Perez Jorge, Department of Teaching and -Educational research, University of La Laguna,

Spain.

Reviewers:

(1) Dare Ojo Omonijo, Olabisi Onabanjo University, Nigeria. (2) Valentine Banfegha Ngalim, The University of Bamenda, Cameroon.

(3) Lufanna Ching-Han Lai, Gratia Christian College, China.

(4) Abraham K. Kisang, Kenyatta University, Kenya.

(5) Uche A. Dike, Niger Delta University, Nigeria.

Complete Peer review History: http://www.sciencedomain.org/review-history/22795

Opinion Article

Received $6^{\text {th }}$ November 2017

Accepted $11^{\text {th }}$ January 2018

Published $20^{\text {th }}$ January 2018

\section{ABSTRACT}

Trickster-like Dharma teachings in Tibetan Buddhism behave as a kind of shortcuts in the approach to leading people along the path of enlightenment. This essay collects three such teachings of different levels towards destroying illusions, i.e., Buddha's silence, Guru's paradox, and Ego's kleshas. They are necessary as "an ace up the sleeve" for Buddha to destruct disciples' metaphysical quagmire, for Guru to lead community toward perfect transcendence, and for individuals to attain self-consciousness.

Keywords: Trickster; Buddhism; enlightenment; consciousness.

\section{INTRODUCTION}

A trickster is any person or thing which acts as not only the rebel against authority but also the breaker of all taboos to enlighten minds through levity, humor, or creative mischief [1]. Appearing as a cunning and/or foolish role played in the myths of different cultural and historical 
dimensions in different concepts, a trickster brings about positive even sacred effects in taking the form of practical jokes or thievery to violate commonly accepted social rules or norms, sometimes maliciously [2].

The definition of trickster varies pertaining to different dimensions in the cultural practice of indigenous people and the metaphysical reasoning of elites' abstractive thinking. Each trickster is unique in a specific practice and/or reasoning. A group of influential ones are illustrated in Fig. 1. Firstly, Jungian psychology is one of the European metaphysical theories, and shares intimate affinities with the Idealist tradition of philosophy [3]. In the Jungian paradigm, the trickster behaves as one figure in the claimed several metaphysical archetypes of the collective unconscious to demonstrate "the importance of the individual psyche and the personal quest for wholeness" [4].

Secondly, in contrast to the description of Native Americans that a trickster takes the form of earthbound human-like animals, e.g., coyote, which is constantly trying but always failing to transcend the fate by attempting to fly, [5] Hyde presents a cultural definition which extends the trickster as one of the gods or the messenger of the gods, which is "the mythic embodiment of ambiguity and ambivalence, doubleness and duplicity, contradiction and paradox" to perform as both a boundary-crosser and a boundarycreator of the world by crossing physical and/or social boundaries [6]. Based on his discussions, artists and some creative individuals often have much of the trickster in them [7].
Thirdly, among the eastern philosophers cultivated by ancient Chinese culture, there exists a cluster of Taoist Scholé (Leisure) sages who are considered as trickster-type characters, like Zhuangzi (c. 369-286 BC). The definition of the trickster here is purely metaphysical, but different from both Jung's psychological concept and Hyde's mythic idea, on that it refers to Aristotle-like synoptic thinkers who are able to develop an over-arching theory that ties together all aspects and fields, [8] while employing various modes of rhetoric, mostly expressed through philosophical demonstrations, to "establish and legitimate normative authority for the particular way of life" endorsed by them [9].

Lastly, the word of trickster is used in Tibetan literature and religion respectively for different purposes. On the one side, there is a popular group of tricksters which exist in Tibetan folk tales. Among them is the famous AkhuTönpa who demonstrates his wicked humors in the daily life to help serfs and all the poor people in the struggle of survival against greedy, cunning, and scoundrel lords [10]. On the other side, the stylistic and thematic hybrid during the $7^{\text {th }}-15^{\text {th }}$ centuries between the Han-Mahayana Buddhist culture and the indigenous pre-Buddhist Bön culture leads to the formation of three types of special tricksters as the "Illusion" destroyers in Tibetan Bön-Buddhist (simply hereafter, Buddhist) religious practices: the subtle Buddhatrickster, the charismatic Guru-trickster, and the abstruse Ego-trickster.

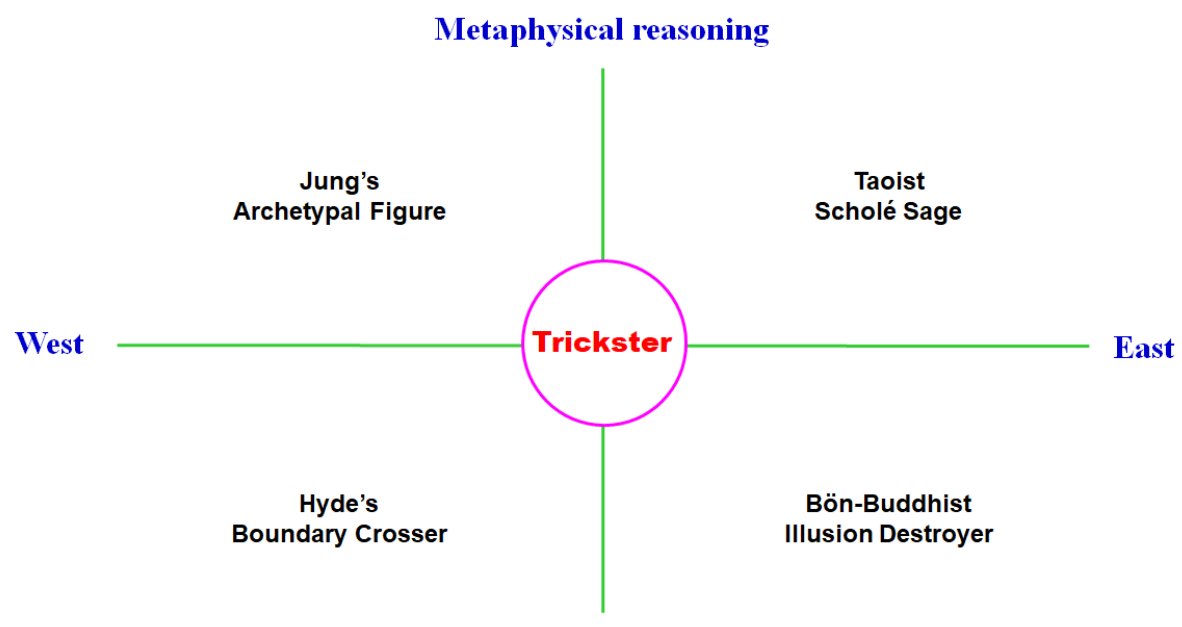

Cultural practice

Fig. 1. Nomenclature of tricksters in cultural practice and metaphysical reasoning 
This essay introduces the unusual trickster-like teachings in Tibetan Buddhism to lead people along the path of enlightenment. The methodology employed to carry out the study lies in the following two steps: (1) Offering a general characterization and classification of different types of tricksters; (2) Exposing the significance of the trickster-like teachings to guide beings away from rigid, irreconcilable facets in reality. The layout of the paper is as follows. Section 2 focuses on Buddha's trickster-like teaching presented in his tricking silence to metaphysical questions. Section 3 describes Guru-trickster teaching, by taking Dalai Lama as an example, shown in his tricking argument on the cosmic evolution. Section 4 elaborates the Ego-trickster and its tricking properties in the transcendence of self-consciousness. Finally, Section 5 gives conclusions.

\section{BUDDHA-TRICKSTER TO DESTRUCT METAPHYSICAL QUAGMIRE}

Fundamentally as a literary character in the early Pali Canon of Buddhism [11], Buddha appears as a compassionate trickster whose actions embody the paradoxical and/or provocative states of the unconditioned, both deceptive and illusive, tricks to "enable those who experience them to put an end to defilements through unmistakable and often funny encounters with their own impermanent limitations" along the path to awakening [12].

The dominant trick Buddha used is his silence when facing 14 metaphysical questions, a treatment of the fundamental Buddhist tradition to destroy metaphysical illusions and stimulate spiritual growth for enlightenment. It influences Madhyamika, Yogacara, and in particular, Zen Buddhism [13], These questions are divided into four groups: [14] Group 1 deals with Time, including (1) Is the Universe eternal? (2) Is the Universe non-eternal? (3) Is the universe at one and the same time eternal and non-eternal? (4) Is the Universe neither eternal nor non-eternal? Group 2 deals with Space, including (5) Is the Universe infinite? (6) Is the Universe finite? (7) Is the Universe at one and the same time infinite and finite? (8) Is the Universe neither infinite nor finite? Group 3 deals with Soul \& Body, including (9) Are the soul and the body identical? (10) Are the soul and the body non-identical? And, Group 4 deals with the Survival of Buddha, including (11) Does Buddha survive death? (12) Does Buddha not survive death? (13) Does Buddha both survive and not survive death? and, (14)
Does Buddha neither survive nor not survive death? [15].

The Buddha's silence demonstrates the core of Buddhist doctrine, the Middle Path between Eternalism or Nihilism, to manifest the principle of Dependent Origination (Pratītyasamutpāda) in the way of destroying illusions and transforming insights into Emptiness (śūnyatā). The silence ignores the principle of non-contradiction, and offers a paradoxical view to illustrate the ineffable reality of some logical questions like, either $A$ or $B$; neither A nor B; or, not neither A nor B: [13] on the one hand, the silence implies to admit some validity of the words, symbols, or metaphors to describe the ineffable reality; on the other hand, it entails that the words, symbols, or metaphors are not the perfect tools to describe the ineffable realm.

The trick of silence reflects the wisdom of Buddha to destroy the illusions for the exact answers of these metaphysical questions which are helpless in spiritual awakening: First of all, the questions do not have much to do with the basic teachings of the Buddha: (1) Three Dharma Seals (Tri-drsti-namitta-mudrā), i.e., impermanence, non-self, and nirvana; (2) Four Noble Truths (cattāriariyasaccāni), i.e., suffering, cause of suffering, end of suffering, and, the path that leads to the end of suffering; (3) Noble Eightfold Path (ariyoațthanigikomaggo), i.e., right view, resolve, speech, conduct, livelihood, effort, mindfulness, and, prefect meditation; and, (4) Twelve Nidānas (pațicca-samuppāda-añga), i.e., ignorance, fabrication, rebirth consciousness, name \& form, six entrances, contact, sense, craving, attachment, becoming, birth, and agingdeceasing. Secondly, the questions are so abstract that they lead people to go astray, lose the way, and waste the time in the egotranscending practice (Sādhana) during the short secular life. Thirdly, they are so inscrutable due to the limitations of language, which is bounded merely within the ranges of familiar things and ideas confined to time, space and origin, that normal people are unable to understand the answers. Finally, Buddha is not a computer to reply any kinds of questions without thinking; instead, he is a practical teacher full of compassion and wisdom, and pay attention mainly to what are helpful for the questioners to follow the right path toward destroying illusions to gain enlightenments.

Therefore, behaving as a trickster, Buddha adopts silence to treat metaphysical problems. This response supersedes any eloquence for the 
listeners. More importantly, the tricking silence displays Buddha's deep concerns and considerations to the puzzlers entangled in the mesh of logical and/or metaphysical issues.

\section{GURU-TRICKSTER TO ATTAIN PERFECT TRANSCENDENCE}

The deluded ego makes our secular people to own a mind which is chaotic. Ignorance and darkness blind our eyes to hardly see ourselves clearly, but trust illusions which resist the selfrealization. As the destroyer of illusion, the guru is both a mirror to reflect our inner self and a trickster to gleefully goads us to grow the perception of emptiness beyond hope and fear and the awareness of the universal law of the dependent origination.

In his masterpiece, The Universe in a Single Atom [16], His Holiness the Dalai Lama admitted that "our universe ... is continuously evolving and expanding," a similar view to that assumed by the modern big-bang cosmological model. However, he provocatively argued that "the idea that there is a single definite beginning is highly problematic": if such an absolute beginning exists, only two options are possible, theism and causationlessness. While the former "proposes that the universe is created by an intelligence that is totally transcendent" and therefore against the law of cause and effect, the latter "is that the universe came into being from no cause at all", also in opposition to the law of cause and effect. This paradoxical argument does force readers to turn to Tsong kha pa's doctrine on Wisdom of Emptiness [17] so as to be able to destroy the accompanying illusions in the full spectrum of consciousness.

Set forth by the Buddha and explicated by Nagarjuna of Madhyamaka, the most profound Buddhist wisdom was the knowledge of Emptiness. It refers to the fact that everything in the universe, from various physical forms to the omniscient consciousness of the Buddha, is contingent without exception, and featured by the dependence for its existence on its causes, its parts, or a designating consciousness, while devoid of an independent or intrinsic nature; that is to say, nothing in reality is able to stand alone by itself and on itself, and to exist in and of itself [17].

The tenet of the Emptiness philosophy is the emptiness of the Emptiness: "it does not have an existence on its own, nor does it refer to a transcendental reality beyond or above phenomenal reality" [18]. The state of the full consciousness of the intensive and extensive emptiness is characterized by the DharmaRealm Essence [19] without birth or death, without being or non-being, without defilement or purity, and, without increasing or decreasing.[20] In the Yogachara (or, Consciousness-only) School, it refers to the Amala consciousness, corresponding to the state of Tathāgatagarbha, the ultimate, pure, ungraspable, inconceivable, irreducible, unassailable, boundless, true and deathless quintessence of Buddha's emancipatory reality [21]. This is the state of Nirvana to manifest four perfect transcendences: [22] Perfect permanence due to the realization of the samsara-nirvana unity; Perfect happiness due to the disappearance of the five aggregates and their causes; Perfect self due to the transcendence of the conceptual constructions of the self and non-self; and, Perfect purity due to the pure dharmakaya in nature.

Therefore, thanks to the trickster-like wisdom of His Holiness the Dalai Lama, it is evident that the Buddhist Emptiness philosophy does not refer to that "everything is empty;" by contrast, it demonstrates that all things, including the bigbang cosmogenesis, of the Universe are dependently arisen. It was more than 2000 years ago, prior to the emergence of science on the Earth, that this unique, profound insights began to shed light on the secular world for the continuous birth and death, happiness and suffering, and prosperity and dissipation of both nature and mankind. Without exaggeration, gurutrickster plays a key role in the secular world to unlock the truth of the mysterious universe. Under the guru-tricksters' paradoxical and/or provocative robe of Emptiness, it is clearly seen that everything is made from mind alone, and the myriad dharmas are only from the mind to reveal the law of the dependent origination.

\section{EGO-TRICKSTER TO DEVELOP SELF- CONSCIOUSNESS}

The ego is the most difficult trickster for us to recognize. This is because the ego-trickster cannot be aware of via the five sense organs. However, it appears as "both our closest friend and our worst enemy" [(2) in ref.1]. It is the illusion that hides in mind (the compound word of cittas), and disguises its thoughts and feelings as our realistic ones [23].

Ego-trickster is the external expression of one of the eight Consciousnesses, while the undefiled 
ingredient of the $8^{\text {th }}$ consciousness, Alaya, is ascribed as the $9^{\text {th }}$ one, Amala (or, the pure consciousness) [24]. The additional seven Consciousnesses include the five sensational ones and two minds, Mano and Manas, the root of which is Manas. The twins and Alaya are described as the three cittas [25]. Manas is equivalent to "transference," owning neither inner Essence (or Substance) nor outer function (or Karma), but makes use of Alaya as its internal essence, and takes advantage of Mano to show its external function. Particularly, the twins are characterized by the non-equanimity with Manas dominated rationally or logically by the left brain, and with Mano dominated sentimentally or perceptually by the right brain [26]. Table 1 lists all of the nine consciousnesses in five levels [27].

The ego-trickster is the external expression of Manas, Level 3, characterized by the concept of the Self while, on the one hand, gaining previous and present experiences through Mano and the five senses; on the other hand, universalizing the experiences through intuitive and abstract perceptions of the universal mind of Alaya to discern the inner world [28]. The ego-trickster keeps the full function of Upadana ("attaching" plus "clinging" plus "grasping"[29]) to giving rise to five fundamental Kleshas (poisons or negative emotions): (1) Chi: ignorance, folly, confusion, bewilderment, or delusion; (2) Chen: dislike, aversion, anger, or hatred related to the turbidity, prejudice, prohibition, deviance, discrimination, or dualism of views; (3) Tan: attachment, greed, desire, or passion; (4) Man: pride, arrogance, conceit; and (5) Yi: envy, doubt, indecision [30]. Whenever the mind of the Self is present, there follows at the same time these Kleshas to obscure and delude the absolute Bodhi Citta of Emptiness, resulting in the arising of the inability in the Mindsight (a concept to understand the mind of the self and others and see the reality of Nature) [31]. Consequently, as the subtle and mischievous prime mover, the ego-trickster drives to grow the perceptual illusions of the outer world and entrap the mind mired "in delusions either of grandeur or of insecurity and self-doubt" [32].

It is therefore mandatory to destroy the illusions of the sentimental beings by transcending the ego-trickster with the cultivations of Precepts, Samadhi, and Wisdom [33]. Among the numerous approaches, the most efficient and effective one is the use of Mandala and subtle energies of the mind, of wind, and of the channels, to transform Kleshas to a valuable vehicle (yana) via achieving 3-level kayas of the truth body (Dharmakaya), the enjoyment body (Sambhogakaya), and the emanation body (Nirmanakaya), thus reaching the enlightenment of consciousness after the 3-stage practices of foundation, path, and result [34]. Embodied by five Buddha families, Mandala is a tantric construction of the energy grid to represent the constant cosmic flow of divine and demonic, human and animal impulses as they interact with the sentimental world in both constructive and destructive patterns [35]. The 5 Buddha families, as well as the corresponding 5-level consciousnesses in Table 1, are presented in Table 2 [36].

A famous Tibetan Buddhist ritual to transcend the ego-trickster and destroy the illusions was held annually in the Everest Solu-Kumbu region of Nepal, officiated by Trulshik Rinpoche.[37] In practice, because Buddhism is not an ahistorical unchanging tradition in time, space, and texts versus lived reality,[38] the Tantric festival demonstrated several indigenized and simplified characteristics owing to the cultural localization influenced by the Shamanism-like Bon religion, while still presenting the theme of traditional Tantric practice: [39] (1) Among the Kleshas, only the illusion (or ignorance) of human beings

Table 1. Five levels of the nine types of consciousness (with the row of Level 3 in red)

\begin{tabular}{llll}
\hline Level 5 & $9^{\text {th }}$ & Amala or pure consciousness & free from all karmic impurity \\
Level 4 & $8^{\text {th }}$ & Alaya or repository consciousness & through reflective awareness \\
Level 3 & $7^{\text {th }}$ & Manas or self consciousness & through deluded awareness \\
Level 2 & $6^{\text {th }}$ & Mano or perception/ideating consciousness & through the senses in Level 1 \\
& $5^{\text {th }}$ & Body or touching consciousness & due to tactile stimulus \\
& $4^{\text {th }}$ & Tongue-or-tasting consciousness & due to gustatory stimulus \\
Level 1 & $3^{\text {rd }}$ & Nose-or-smelling consciousness & due to olfactory stimulus \\
& $2^{\text {td }}$ & Ear-or-hearing consciousness & due to auditory stimulus \\
& $1^{\text {st }}$ & Eye-or-seeing consciousness & due to visual stimulus \\
\hline
\end{tabular}


Ma; ARJASS, 5(1): 1-9, 2018; Article no.ARJASS.38108

Table 2. Five buddha families in Mandala (with the column of Level 3 in red)

\begin{tabular}{|c|c|c|c|c|c|}
\hline Property & Level 5 & Level 4 & Level 3 & Level 2 & Level 1 \\
\hline $\begin{array}{l}\text { Family } \\
\text { Bodily Acts }\end{array}$ & Buddha 3 & Vaira 2 & Ratna 4 & Lotus 1 & Karma 5 \\
\hline $\begin{array}{l}\text { Five Tathagatas } \\
\text { Kayakarmam }\end{array}$ & Vairocana & Akshobhya & Ratnasambhava & Amitabha & Amoghasiddhi \\
\hline $\begin{array}{l}\text { Verbal Acts } \\
\text { Vak karmam }\end{array}$ & Samantabhadra & Manjusri & Akasagarbha & Avalokitesvara & Vajrakarma \\
\hline $\begin{array}{l}\text { Mental Acts } \\
\text { Manokarmam }\end{array}$ & Acalavajra & Trailokya-vijaya-raja & Kundali Vidyaraja & Yamantaka & Guhyapada \\
\hline Consciousness & Amala & Alaya & Manas & Mano & 5-Organ senses \\
\hline Wisdom & $\begin{array}{l}\text { Dharma-Realm } \\
\text { Essence }\end{array}$ & Great, Perfect Mirror & Equality & Discrimination & Accomplishment \\
\hline $\begin{array}{l}\text { Position } \\
\text { Color } \\
\text { Element } \\
\text { Body Organs }\end{array}$ & $\begin{array}{l}\text { Center } \\
\text { Yellow } \\
\text { Earth } \\
\text { Spleen } \\
\text { Stomach } \\
\end{array}$ & $\begin{array}{l}\text { East } \\
\text { Blue } \\
\text { Wood } \\
\text { Liver/Gall } \\
\text { Bladder }\end{array}$ & $\begin{array}{l}\text { South } \\
\text { Red } \\
\text { Fire } \\
\text { Heart/Pericardium } \\
\text { Small Intestine }\end{array}$ & $\begin{array}{l}\text { West } \\
\text { White } \\
\text { Metal } \\
\text { Lung } \\
\text { Large Intestine }\end{array}$ & $\begin{array}{l}\text { North } \\
\text { Black } \\
\text { Water } \\
\text { Kidney } \\
\text { Urinary Bladder }\end{array}$ \\
\hline
\end{tabular}


was suggested to limit their potential of imaginations and wills for the mind empowerment of transformation; thus, destroying the illusion is the highest form of magic; (2) The compassion of all the Buddhas was personified specifically as the Lord of the Dance, named Garwang Tojay-chenpo, the deity of Mani-Rimdu whose infinite creativity is symbolized by dance; (3) Trulshik Rinpoche was regarded to embody the Lord of the Dance and destroy the illusion in the tantric battles via dances with the malevolent supernatural forces of the Universe at Thubten Chiwong Monastery each autumn; (4) The three dimensional mandala was reduced to a design of a brightly colorful painting with sand, prepared painstakingly on a two dimensional plane grain by grain and mantra by mantra; however, the elaborated final product was destroyed to symbolize sending the mandala gods back to their realm; and, (5) Mental empowerment or spiritual sustenance was assumed to be able to be reached by taking man-made mani pills which were considered to have absorbed the power of the god to help people, and therefore to be treasured and kept for taken in time of need [40].

\section{CONCLUSION}

Buddhist tricksters are different not only from the cunning and/or foolish tricksters in folklores or legends, but also from the western Jungian archetypal figures \& Hyde's boundary-crossers, as well as from the eastern Taoist Scholé sages. They cover a wide range of characters, from the Buddha to the self, in the Tibetan Buddhist religion. It is shown that the Buddhist tricksterlike teachings act as "an ace up the sleeve" to provide shortcuts towards destroying illusions, and to mitigate the most awkward or perplexing tension emerging between the Buddha and his disciples, between the teachers and their audience, and between the awakened and defiled states of consciousness. The threedominant trickster-like teachings are featured by the following:

(1) Buddha trickster-like teaching, with the most representative trick expressed by the subtle silence to destruct metaphysical quagmire in the exhibition of his cosmic wisdom and compassion;

(2) Guru trickster-like teaching, with the most representative trick performed charismatically by Dalai Lama on the recognition of Emptiness in the sentient world;
(3) Ego trickster-like teaching, with the most representative trick in self-consciousness to differentiate the three abstruse cittas and twins of the mind in the external expression of the self.

\section{ACKNOWLEDGEMENT}

The work was inspired by Professor Steven D. Goodman's public lectures on Buddhist tricksters in Spring 2017, CIIS. The author expresses sincere thanks to the editor and five anonymous referees for the important advice and comments.

\section{COMPETING INTERESTS}

Author has declared that no competing interests exist.

\section{REFERENCES}

1. Erdoes R, Ortiz A. American Indian myths and legends. New York: Pantheon Books. 1984;335. (2) Goodman S. The trickster in Tibetan Buddhist practice: working with paradox, provocation, and humor. Syllabus CIIS Public Programs and Performances (WKS 025 01: 18-19 February). California Institute of Integral Studies, San Francisco; 2017.

2. N.a. Trickster. New World encyclopedia; 2014.

Available:http://www.newworldencyclopedi a.org/p/index.php?title=Trickster\&oldid=98 $\underline{3191}$

3. Mills J. Jung's metaphysics. Int J Jungian Studies. 2013;5(1):19-43.

4. Stevens A. Jung: A very short introduction. Oxford: Oxford University Press. 1994;152.

5. St. Rosemary Educational Institution. Carl Jung's Archetype: The Trickster; 2017. Available:http://school workhelper.net /carljungs-archetype-the-trickster/

6. Hyde L. Trickster makes this World: Mischief, myth and art. New York: Farrar, Straus and Giroux. 2010;2.

7. Blum SD. Lies that bind: Chinese truth, other truths. Lanham: Rowman \& Littlefield Publishers, Inc. 2007;142.

8. Yeh Chih-Kuei. Zhuang-zi Xiao-yao You Yu Aristotle's Schole (Chuang Tzu's Hsiao Yao and Aristotle's Schole): Kua Wen-hua Xiu-xian Zhe-xue Fen-xi (A Cross-cultural Analysis of Leisure Philosophies). In Chinese. Hu-wai Xiu-xian Yan-jiu (Outdoor Leisure Study). 1995;7(3):79-89. 
9. Kohn L. New visions of the Zhuangzi. St. Petersburg, FL: Three Pines Press. 2015; 136.

10. Kunmchogdgelegs, Dpalldanbkrashis, Kevin Stuart. Tibetan Tricksters. Asian Folklore Studies. 1999;58:5-30.

11. Gray P. Varieties of religious invention: Founders and their functions in history. Oxford: Oxford University Press. 2015;54.

12. McClintock SL. Compassionate trickster: The Buddha as a literary character in the narratives of early Indian Buddhism. J Amer Acad Reli. 2011;79(1):90-112.

13. Park K. An analysis of the Buddha's paradoxical silence: Neither the positive nor nihilistic view. Int J Buddhist Thought \& Culture. 2006;6:243-264.

14. Organ TW. The silence of the Buddha. Phil East and West. 1954;4(2):125-140.

15. CBETA, Han-wen Da-zang Jing (Chinese Buddhist Canon). In Chinese. T02n0099 007, Za A-han Jing (saṃyuktāgama), volumes 7, 168, 169.

Available:http://tripitaka.cbeta.org/T02n009 9 007: (1) Shi-jian Chang; (2) Shi-jian Wuchang; (3) Shi-jian Chang Wu-chang; (4) Shi-jian Fei-chang Fei Wu-chang; (5) Shi You-bian; (6) Shi Wu-bian; (7) Shi Youbian Wu-bian; (8) Shi Fei You-bian Fei Wubian; (9) Ming Ji-shi Shen; (10) Ming-yi Shen-yi; (11) Ru-lai Si-hou You; (12) Ru-lai Si-hou Wu; (13) Ru-lai SI-hou You-wu; (14) Ru-lai Si-hou Fei-you Fei-wu.

16. Dalai Lama. The Universe in a single atom: How science and spirituality can serve our world. New York: Morgan Road Books; 2005.

17. Lopez DS. A tantric meditation on emptiness. In: White DG ed. Tantra in practice. Princeton: Princeton University Press. 2000;524-542.

18. Garfield JL. Dependent arising and the emptiness of emptiness: Why did Nagarjuana start with causation? Phil. East West. 1994;44(2):219-250.

19. Williams P, Tribe A. Buddhist thought: A complete introduction to the Indian tradition. London \&New York: Routledge, Taylor \& Francis Group. 2002;211.

20. (1) Red Pine (translator and Commentator) 2005. The heart sutra: Womb of Buddhas. Berkeley: Counterpoint. (2) Thich Nhat Hanh (translator). New Heart Sutra translation; 2014.

Available:http://plumvillage.org/news/thichnhat-hanh-new-heart-sutra-translation/
21. N.a. Tathagatagarbha doctrine. In: New World Encyclopedia; 2015.

Available:http://www.newworldencyclopedi a.org/ entry/Tathagatagarbha doctri-ne

22. (1) Floistad G. Philosophy of religion. In: Contemporary Philosophy: A new survey. Dordrecht: Springer. 2010;10:250. (2) Arya Maitreya, Acarya Asanga. n.d. The ultimate mahayana treatise on the changeless continuity of the true nature: The changeless nature (The mahayanottaratantra sastra). Translated from the Tibetan texts by Holmes $\mathrm{K}$ \& Holmes K. Karma Drubgyud Darjay Ling. p.9.

23. Flaherty M. n.d. Quotes on the Ego from the movie Revolver.

Available:https://www.academia.edu/25214 582/Quotes on the Ego

24. Nichiren Buddhism Library. AmalaConsciousness. Dictionary of Buddhism. Available:http://www.nichirenlibrary.org/en/ dic/Content/A/44

25. Tripitaka Master Xuanzang. Tang Dynasty. Verses Delineating the Eight Consciousnesses. In: (1) Pu-tai. Comments on the Eight Consciousnesses (in Chinese). CBETA, T45, no.1865. Available:http://www.cbeta.org/result/T45/T 45n1865.htm (2) Vajra Bodhi Sea 1997: December 37-38; 1998: January 35-36; February 34-35; March 33-34; April 34-35; May 31-32; June 31-32 \& 45; July 31-32; August 32-33; September 36-37; October 38-39 \& 42. Epstein R. English translator; Zeng W, Wang Q: Chinese translators. Note: (1) The Verses does not have an offprint version; (2) The Verses is the summary of Xuanzang's the treatise on consciousness-only doctrine on the request of his foremost disciple and successor Dharma Master Kuiji (632-682).

26. Master Chin Kung 2016. Eight Consciousnesses (in Chinese).

Available:http://tw.jingzong.org/ltem/2601.a spx

27. Ma ZG. Nine Buddhist consciousnesses and four psychological forces: A review. Asian Res J Arts Soc Sci. 2016;1(5):1-15.

28. Buddhadasa Bhikkhu. The prison of life. Santikaro, translator. Bangkok: The Buddhadāsa Indapañño Archives \& Wisconsin: Liberation Park; 2014.

29. Ref.19, p.45, p.67.

30. Longchen Yeshe Dorje. Treasury of precious qualities. Boulder: Shambhala. 
p.492. Note: they are named "Five Poisons (Chi-Chen-Tan-Man-Yi)" in Chinese; 2010.

31. (1) Siegel DJ. Mindsight: The new science of personal transformation. New York: Bantam Books. (2) that is, Ming-xin Jianxing in Chinese. Hsuan Hua 1958. Nian Pu-sa Neng Ming-xin Jian-xing (Recite the Bodhisattva's Name to Understand the Mind and See the Nature). In: Venerable Master Hua's Talks on Dharma. Dharma Realm Buddhist Association. 2011;1. Available:http://www.drbachinese.org/onlin e reading simplified Idharma talks/kaishrlu-1/volume1-ce-10. htm

32. Ed \& Deb Sharpiro. What It Means To Have A Guru In Your Life. Qatar Tribune. 14 of July, 09; 2011.

Available:http://w.qatartribune.com/data/20110714/pdf/ main.pdf

33. That is, Jie-ding-hui in Chinese. Hsuan Hua. Xue-fu Yao-xiu Jie-ding-hui (To Study Buddhism, We Must Cultivate Precepts, Samadhi, and Wisdom). ZHi-hui Zhi-yuan (Power of Wisdom). 1993;187:2.

Available:http://www.drbataipei.org/ wisdom/187/wisdom187 2.htm

34. (1) Tony. Introduction to the Buddhist path: Introduction to Tantra. In: Dharma Teachings at TBC, TBC Introduction to Buddhism Series; 2011.

Available:http://www.tibetanbuddhist.org/int roduction-buddhist-path-introductiontantra-pdf (2) Ref.19, p.204. (3) White DG. Tantra in Practice. Princeton and Oxford: Princeton University Press. 2000;7.
35. Ref. 34(3), pp.3-38.

36. The Table is updated from Table 1 in Ref.19, p.211 in reference of Figures 2.12.14 in: Maciocia G. The fundamentals of Chinese medicine. $3^{\text {rd }}$ ed. New York, London, et al.: Elsevier. 2015;22-33.

37. (1) Kohn RJ. Lord of the Dance: The Mani Rimdu Festival in Tibet and Nepal. New York: State University of New York Press. (2) Kohn R (Actor) 2006. Destroyer of Illusion. DVD; 2001.

Available:https://www.amazon.com/Destro yer-Illusion-RichardKohn/dp/B000HOMSRW (3) Goodman W 1987. Film: Documentary on Tibetan Ritual. New York Times. Movies.

Available:http://www.nytimes.com/ 1987/12/26/movies/film-documentary-ontibetan-ritual.html

38. Anderson K. Tibetan Buddhism. Buddhist Studies 114. Berkeley: University of California, Lecture notes; 2016.

39. (1) Goldberg M. Reviewed work: Lord of the dance, destroyer of Illusion by FranzChristoph Giercke. American Anthropologist New Series. 1988;90(3): 782-784. (2) Wilmington M. Lord of the dance: A journey to Himalayas; 1987. Available:http://articles.latimes.com/198710-03/entertainment/ca-2784 1 tantricdance

40. Note: these pills were treated as the symbols of the Nectar pills as introduced in Mahayoga, the early stage of the Highest Yoga Tantra.

(C) $2018 \mathrm{Ma}$; This is an Open Access article distributed under the terms of the Creative Commons Attribution License (http://creativecommons.org/licenses/by/4.0), which permits unrestricted use, distribution, and reproduction in any medium, provided the original work is properly cited.

Peer-review history:

The peer review history for this paper can be accessed here: http://www.sciencedomain.org/review-history/22795 